\title{
Editorial
}

\section{Feminist Comics in an International Frame}

\author{
Sally R Munt ${ }^{1 *}$, Rose Richards ${ }^{2}$ \\ Published: April 11, 2020
}

This special issue, which has been jointly edited by Sally R Munt, Rose Richards and comic artist Nicola Streeten, is focussed on exploring how comics and graphic narratives have engaged with feminist politics. We have brought together artists and critics from a range of countries to discuss and debate how artists represent and debate gender, with examples of comics taken from Japan, Nepal, India, UK, China, Mexico, Democratic Republic of the Congo, Egypt, Argentina, Turkey, Hong Kong, and South Africa. We are thrilled to bring this content to our readers; the special issue offers a snapshot of how international comic art can politicise gender in the twenty-first century. Framing our special issue on comics is an exploration of global comic diversity and local specificity, as each of the texts discussed exists in a dynamic intertextuality between the local and global production and consumption of popular culture.

Comics usually take the form of sequential panels in order to create a narrative. Sometimes for example with stylistic rhetoric such as caricature, comics can consist of a single satirical drawing or cartoon intended to communicate a punch line or joke. In-text formalistic devices such as captions, speech balloons or movement shadowing enhance the chronological sense of movement of a story. Comics are an ancient genre, arguably European cave paintings in Lascaux, France, with their vibrant action scenes, are the earliest form of comic. The famous Bayeux Tapestry, depicting the Norman Conquest of England, is a 70 metre long early form of 'war comic'. Stained glass windows in medieval cathedrals and wealthy churches can be interpreted as early comics too, constructed as they were by the all-powerful Church in order to instruct the illiterate poor in the religious paradigms and folktales invested within the Holy Bible. One of the guest editors of this special issue is descended from the Anabaptist stained glass artists who built St Albans Cathedral, in England. Egyptian hieroglyphs are iconic, figurative, logographic and symbolic engravings and papyrus inscriptions of consequential scenes, instructing the population in the key concepts of deity and the power of the pharaohs, and the natural pagan order. The sacred writing of hieroglyphs was the popular culture of Ancient North Africa. And comics were also developed in their earliest forms in Japan with the appearance of manga in the $12^{\text {th }}$ century. But comics as a modern mass media genre didn't really take off and become a trend until the 1930s, when in western culture early forms of leisure combined with the widespread production of newspapers, and new forms of disposable income which entertained the newly literate public.

Growing up in the North of England in the 1960s, Sally Munt was a typical Yorkshire child who was allowed two comics a week, firstly Bunty for girls, and then for many years Beano and Dandy, complemented by the much anticipated yearly highlight: the Christmas Annual. Later, being a tomboy, in latency Sally moved onto boy's comics such as Victor, and Hotspur where she learned many German phrases from the war stories ('donner und blitzen' becoming a lifelong habit), and tried to make some sense out of the football strips. But dominant culture prevails, and so Sally became yet another teenager whose weekly foray into the girly Jackie magazine (ineffectively) schooled her into the paradigm of English femininity. Many of these popular British comics were in fact more specifically Scottish, and it is challenging to reproduce now the formative quality of these texts upon whole generations of children. Perhaps in thinking about comics for adults as a niche or underground we fail to recognise that those 'mainstream' comics were both hegemonic, and also in their own ways radical. Figures like Minnie the Minx - a furious little class warrior whose tomboy antics delighted both boys and girls - or Beryl the Peril, from Topper, a lovable menace with a pet turkey called Gobbler, whose naughtiness never failed to disappoint in creating mayhem, destruction and misrule, were staples in the readership patterns of young girls that originated in the 1950s, in most cultural histories of the west, a post-war decade widely remembered as being unprecedentedly conservative.

${ }_{1}$ Professor of Cultural Politics at the University of Sussex, UK

${ }^{2}$ Writing Lab at the Stellenbosch University Language Centre, SOUTH AFRICA

*Corresponding Author: s.r.munt@sussex.ac.uk 
Thus, it is important to understand a key methodological insight from Cultural Studies - that even though cultural texts may be designed for specific audiences, and appear to be conventional in targeting content to such predestinations, media artefacts and cultural objects nevertheless contain opportunities for moments of consumption that challenge and disrupt preconceived ideas and beliefs. So, for Sally's experience of childhood, gendered narratives from comics were consumed in unpredictable and unstable combinations, and in her case, signally failing to construct the social subject of 'girl'. Because of such instances, although markets produce commodities for an imagined consumer, or a preferred consumer, patterns of oppositional reading practices or unintended consumption may turn supposedly conservative media objects into instruments of social change. As academics and activists, it is up to us to understand and make an account of such disruptions in representation, and the social conditions that lead to them.

It is the piercing directness of comics that makes them efficient for political messages. This is something that the English social reformer Henry Mayhew, and wood-engraver Ebenezer Landells, understood very well when they started up the weekly satirical magazine Punch (or The London Charivari) in 1841; they were following in the footsteps of the great moral/social, visual critic from the seventeenth century, William Hogarth. Punch was the initiator and disseminator of the popular political cartoon, understood to be a single sketch or drawing that is intended to amuse or ridicule a knowing reader. In the nineteenth century many of the cartoons in Punch directly or indirectly addressed British colonial rule in India, many of those cartoons which addressed colonialism and British Imperialism are available online. ${ }^{1}$ Even in early issues of Punch, if you look at the iconography deployed in these cartoons, you can see themes that critique the colonial project and its failures. Formally, many cartoons function as a simple gag. It wasn't until the film and later the television industries developed in the twentieth century, following the invention of moving image technologies, that 'cartoons' (or more specifically, animation) became the narrativised experience innovated by Disney, now exponentially reproduced via billion-dollar global media businesses.

Nowadays, cutely anthropomorphised animals, and/or superheroes, have become a staple of childhood entertainment worldwide. Amongst childhood peers, transitional objects with cultural capital have changed, so that a lifetime ago a child who had read classic western canonistic novels such as Heidi or Little Women, or Ivanhoe or The Three Musketeers might be regarded quizzically today as eccentric, or perhaps a little weird. Today, consumption of (predominantly American) cartoons has become a ritual of childhoods across the globe, reinforced by synchronous franchise marketing, so that children demand for birthdays and Christmas the merchandise of the cartoons and superheroes they've already watched, in order to cement and validate their social place in the global and local material economy. Anthropologically, comics have been units of exchange for children for a long time, particularly because they are usually so cheap, and durable, and can be passed between many hands before they begin to fall apart. Additionally, marginalised or excluded groups have sometimes chosen to create and circulate comics because the means to do this are widely available and cheap. In that sense, comics as material objects have often been democratic art commodities. Now, children hold plastic and metal electronic tablets in their hands to watch such seemingly ubiquitous heroes, whereas for so many previous generations the material symbolic of childhood media consumption was enabled by the feel of paper between their fingers.

Yet, comics continue to stimulate radical and oppositional energies: organisations such as Comics for Youth Refugees Incorporated Collective ${ }^{2}$ produce stories for children in refugee camps and/or whom have resettled and yet continue to experience trauma. Other initiatives, such as in the UK, PositiveNegatives ${ }^{3}$ produces comics and animations on humanitarian themes that explore ways to represent complex testimonies via sequential art. PostiveNegatives produces comic art that amplifies the voices of activists, presents 'graphic advocacy' to the UK government, and depicts the refugee experience through visual immersion and the power of comics. There are in fact many comic artists all over the world who grasp the potency of comic art to produce creative material for inspired, humanitarian, and pedagogic reasons. This is partly because comic art is accessible to wide audiences, it doesn't require specialist knowledge to interpret, and has a powerful immediacy that can communicate an important message in an economic way.

Comics have been appropriated by radical activists of all political persuasions for a very long time. We know that it is the plasticity of comic art that lends itself toward instant symbolic communication, as witnessed currently with the dichotomous appropriations of Pepe the Frog, a comic figure created by American cartoonist Matt Furie in 2005 in a zine called Boy's Club \#1. In western and specifically USA popular oppositional culture, Pepe the Frog was an Internet meme co-opted by the alt-right to codify far right advocacy and activism on 4chan, and there its use was disseminated widely to connect disparate white nationalist agendas, in spite of the artist's outspoken objections to Pepe being appropriated as a hate symbol. In 2019 however, Pepe the Frog was adopted as a symbol

${ }^{1}$ See https://punch.photoshelter.com/gallery/Imperialism-and-Colonialism-Cartoons/G0000vKN2v8ZjQ.g/ Accessed 20 February 2020.

2 http:/ / www.cyric.us/ Accessed 20 February 2020.

3 https://positivenegatives.org/about/ Accessed 20 February 2020. 
of resistance to Chinese authoritarian rule by the Hong Kong protestors, who were largely unaware of its fascist connotations in the USA. In Hong Kong, Pepe the Frog became a symbol of individual liberty against state intimidation, although arguably both divergent uses, politically right and left, adopted the cartoon in order to protest state power. A 2020 documentary directed by Arthur Jones about the struggle for 'ownership' of Pepe the Frog's symbolism won a US Documentary Special Jury Award at the Sundance Festival, and is worth watching precisely in order to gain understanding of the plasticity of such cultural icons.

The fantasy of a superhero who is able to vanquish one's powerful enemies and fight corruption is perhaps necessary for childhood development and for channelling an early sense of justice. Certainly traditional folktales have such figures at their centre, and those heroes are often depicted as being lone knights operating outside of the law. Such fantasies don't become redundant once readers have grown up, and then have to confront the cruelties and effacements of everyday life. Perhaps the fight between 'good' and 'evil' is a universal in human cultures, and so often comic art grapples with fundamental moral dichotomies for humankind. In 2008, Sally Munt wrote about one particular subcultural lesbian comic icon, Hothead Paisan:

In Hothead Paisan: Homicidal Lesbian Terrorist (1993-5), Hothead is a feminist anti-hero, the comic cleverly satirizes mainstream comic superheroes by returning over and over to violent revenge fantasies enacted against homophobic and heterosexist men, as the caption puts it:

"Hothead Paisan, the cult-comic hero. Defender of the Stigmatized, Marginalized, and Disenfranchised. Bodyguard to the Underbelly. Avenger of All That Is Wrong. ${ }^{4}$

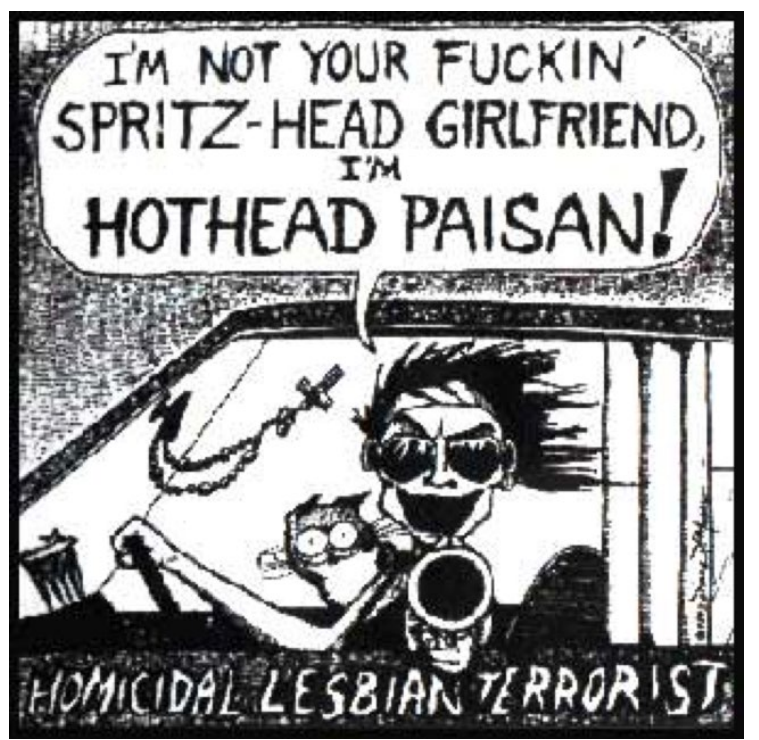

Used with permission (C) Diane DiMassa

The multiple episodes are excessively, viscerally brutal, they are in antithesis to the post-modern gender fluidity emerging at that time, basically all men have penises and that makes them BAD. The men in Hothead's life are irredeemable, un-reconstructable, and morally deserving of their grisly and sadistic ends. The series is vigorously macabre; it captures well the misogynistic violence directed at the feminist and lesbian underclass, and the fearful damage that results. Hothead Paisan is a radical lesbian feminist vigilante, she spares no man, and the violence is frequently absurdist in quantity and quality - one of her comics was banned in Canada as 'hate literature'. Hothead's aesthetic is pure Bataille, William Burroughs, Kathy Acker or Marquis de Sade, it is redolent of transgressive fiction, a political genre that focuses on anomie, and rebellion against social norms. Protagonists of transgressional fiction are frequently portrayed as the excluded, the mentally ill, anti-social and nihilistic, they are habitually mutilated characters, wounded by their epoch. The genre typically deals extensively with taboo subject matters including urban violence and violence against women, drug use, and dysfunctionality. Much of this type of transgressional fiction deals with youthful searches for self-identity, inner peace and/or personal

4 http://www.hotheadpaisan.com/index.html Accessed 27 June 2008.

See further:

Heller, Dana A. (1993). Hothead Paisan: Clearing a Space for Lesbian Feminist Folklore. Folklore, 19:1-2: 27-44; Muscio, Inga. (1999). Review of The Complete Hothead Paisan: Homicidal Lesbian Terrorist by Diane Dimassa. Lambda Book Report, 7(2): 20-22; Sloniowski, Lisa. She Was Framed: An Analysis of Hothead Paisan. Siren (April-May 1996). 
freedom, unbound by usual restrictions of taste; comic illustration, with its ability to go beyond acceptability, is hence an ideal medium for its message. Hothead Paisan belongs gleefully to queer gothic, or splatterpunk in its willingness to portray forbidden behaviours and shock its readers as she lurches from one brawl to another. But Hothead Paisan is a difficult and psychotic character, maniacally fuelled by TV and coffee, she is as much the victimised as the tormenter, and these 'zines portray her acute damage from homophobia as much as they document her resistance. She is the angry lesbian wound.

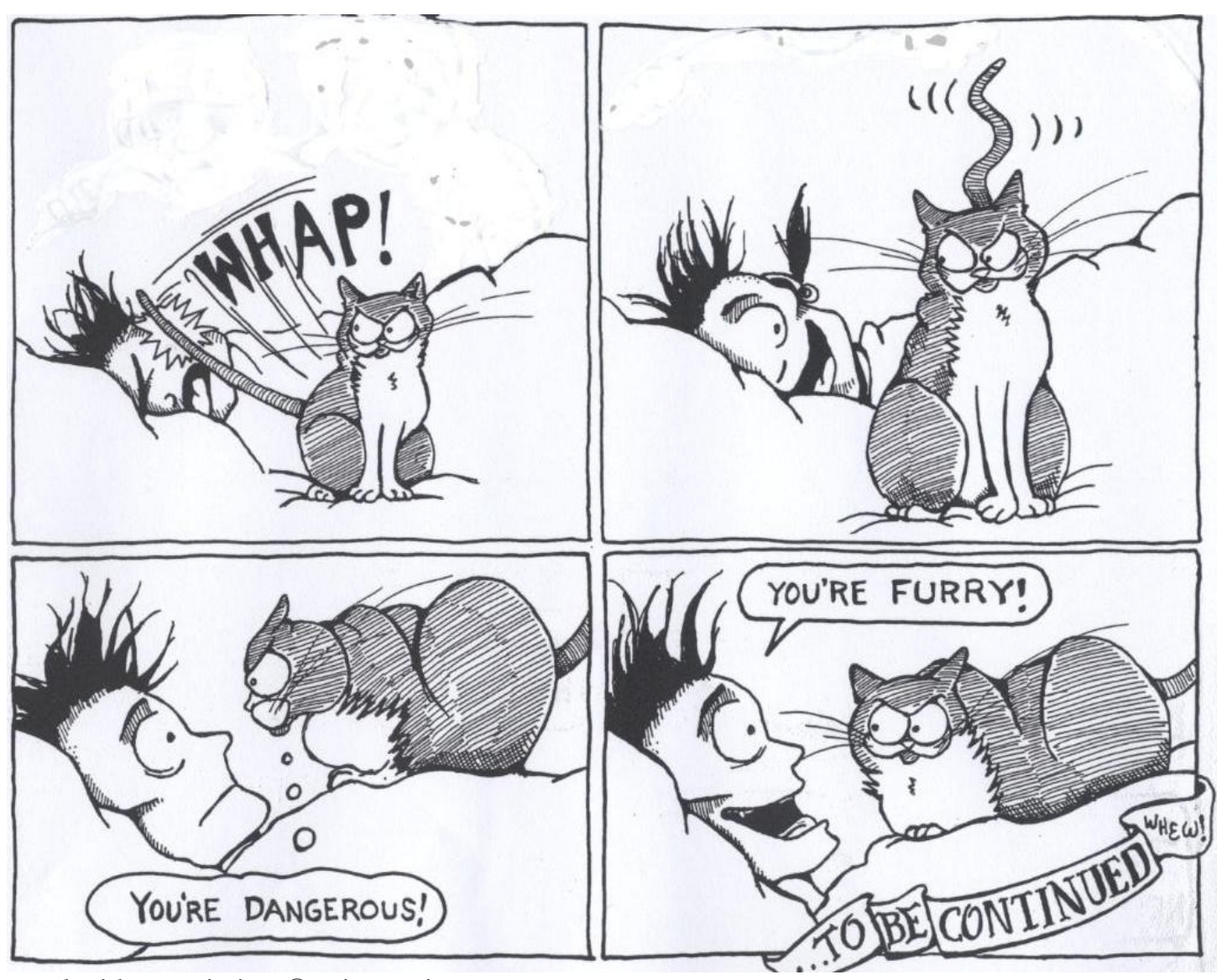

Used with permission (C) Diane DiMassa

At the end of a lesbian avenging angel's day however, she must stomp home, exhausted, to her cat, and in Hothead's case this means the fez-wearing, dancing, karmic 'Chicken'. Chicken is the most fullyfledged lesbian cat in literature, she is the ground, the fundament, the soil of Hothead's existence. Wife, mother, friend, and naughty sibling function, the cat companion Chicken restores, nurses back to health, warns, mends, contains and nurtures her companion's fragility, she is a therapeutic atoll, a warm salve, a Pullman-like daemon to her neurotic lesbian's survival. A cat's constancy can also calm the savage beast of lesbian love, Hothead's human affairs are frequently fraught. The role of Chicken, together with Hothead's blind Buddhist friend Roz, is what gives this series profundity; as their loving relationships grow, and their little queer family is unwrapped, it contains repeatedly moving narratives of recovery from trauma. Despite the pessimistic message that makes this comic sometimes almost too painful to read,

The particular and distinctive love between Hothead and Chicken is a lesbian fantasy of cross-species intimacy that resonates across and down the years. This enchanted couple are the (f)ur-lesbian story. 


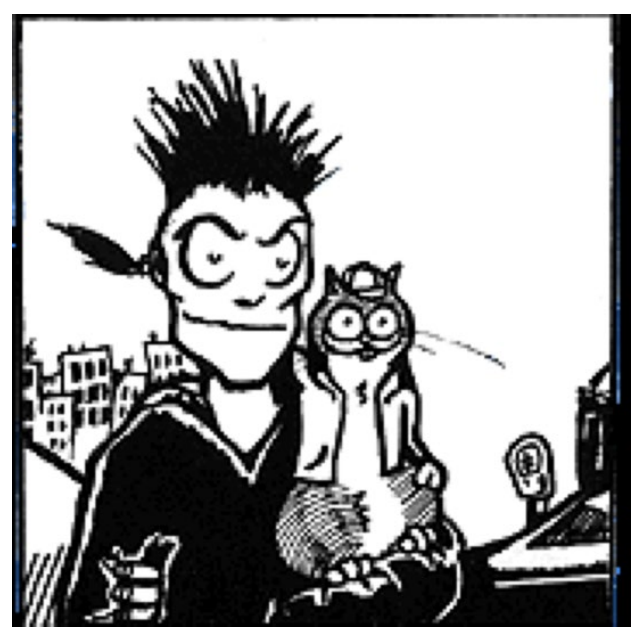

Used with permission (C) Diane DiMassa

If you ask Anglo-American lesbians of a certain age if they are acquainted with Hothead Paisan they will sigh nostalgically for their activist youth and go 'Ah, yes'. Dana Heller wrote an excellent piece at the time that situated this 'urban amazon' within a folklorist tradition. She typologises Hothead as a lesbian feminist comic which could offer cathartic, mythological, heroic resolution to an underclass dystopia 'emblematic of the intense and debilitating sense of powerlessness which almost all lesbians have experienced' (1993: 30). This tough, rangy butch is one paranoid lone avenger who organises our revenge fantasies into a 'last frontier' story, always accompanied of course by her trusty sidekick Chicken. Heller describes how Chicken's allegorical function in the comic

... is to demonstrate alternative coping mechanisms in the face of a relationship defined by an unequal distribution of power and unjust hierarchy that gives human beings - even somewhat deranged beings like Hothead - dominion over their wiser and more civilised pets. (1993: 37)

Chicken tempers the abused dyke mindset with a reality check; she is not simply a salve/slave, she is also the functional representation of animal co-dependence and its associated ethical complications.

This extract from Sally Munt's previous analysis of Hothead Paisan is reproduced here because Sally wanted to include a reminder of how much queer and feminist cultural production has been successfully appropriating and rescripting popular cultural forms. In the early-mid 1990s, following the 'decade of enterprise' in the 1980s, feminist cultural production exploded in the west. In the last two decades of the twentieth century there was a systemic paradigmatic shift in artistic creation and curation, reflecting the political objective that previously marginalised women must be included and properly recognised. But social memories are short, and subcultural memories are shorter because we have fewer cultural institutions to note and commemorate such breakthroughs. Groundbreaking queer and feminist comic artists like Diane DiMassa, whose comic strips were so innovative at that time, are quickly forgotten and remain unacknowledged by younger, queer feminists today. Perhaps it is the ethical duty of older feminist queers to continuously remember and remind, to be the hags who nag! But equally, we require better institutional memories to ensure that such ephemeral cultural interventions are not misplaced or forgotten and our haggish, annoying remembrance function becomes obsolete.

The role of memory in feminist art history is crucial, because we need to diversify our actions - firstly to enable historical revisionism (or as we prefer re-visionism), in order to retrieve the women artists that have been excluded, devalued, or trivialised in the history of art; that exercise in making the invisible, visible, has been going on since the 1970s by some wonderful feminist art historians. Secondly, we need a better 'history of the present' that archives, catalogues, critiques, and enthusiastically engages with women (and men) who are producing counterdiscursive art that foregrounds and problematises heteronormative gender politics, whilst remembering that these artists frequently labour without status or reward, their creative industry remaining still on the margins. And thirdly, we need to improve the epistemological tools that dismantle the archaeological superstructure of art, with its entrenched cultural, symbolic, and economic capitals, in order to better disseminate intersectional, feminist creative practices so that inclusivity becomes more of the norm. Fine art still maintains its elite status, but cultural salvation may still be found by looking to traditionally 'debased' art practices such as comics, and perhaps looking toward digital technologies to democratise the hierarchies of value and embrace popular participation even further. Print has been the chosen communication technology of political dissent since the Industrial Revolution and since the availability of cheap wood pulp to make paper, however the Internet has democratised cartoon and comic art even further, so that digital comics, or e-comics, now proliferate, whether they are accessed through commercial 
platforms such as Amazon's comiXology or Marvel Digital Comics Unlimited, or 'pay what you want' publishing fora such as Panel Syndicate, or Asian platforms such as 'manhwa' in South Korea, or in China 'web manhua' where many titles are available for free. Such digital supermarkets have also offered comic book archive files in which publications are accessible in the long term, for posterity. All of these collections require further cultural analysis.

Feminist art history has only recently begun to uncover and classify the neglected history of women cartoon and comic artists, as Nicola Streeten and Cath Tates' (2018) co-edited 250-year history of The Inking Woman demonstrates. Sheila O'Connell (2018: 10-12) writes about the styles of visual satire and caricature made by, funded by, and about women from the elite social classes of the eighteenth century, with her particular case study of the owner of the 'Macaroni Printshop', Mary Darly, who recognised the commercial potential of satirical prints. The vernacular comedy of artist Marie Duval in the Victorian era is introduced by Simon Grennan, who argues she invented a new drawing style that 'contributed to the creation of a new urban media environment' (2018: 13). Elizabeth Crawford (2018: 14-7) in the same volume provides a short historical analysis of women's suffrage in cartoons, uppity women being something that particularly aggravated readers of Punch magazine. What these short pieces do is open our minds to consider how women's, and feminist, cultural production has been forgotten or in some cases deliberately excluded from genre histories. As feminists, we are still doing the work of uncovering hidden history and re-reading public or commonsense historical traditions, in order to recognise and record the presence of women and also in many cases challenge the gender conventions reproduced in stereotypes of femininity, and sometimes masculinity. Because this work aims to be intersectional, it also changes our understanding of classification, of what is to be included and how we might best draw from that 'sinister wisdom' that problematises such inherited, silencing and often canonistic traditions. Using a critical feminist lens, our aim is to improve and transform knowledge, to expose its powerful orientation to the world that frames particular assumptions about gender, race/ethnicity, sexuality, class and privilege as 'truth'. Thus, by interrogating knowledge in this way, the epistemological process is shifted. This is an important political project to challenge visual narrative as it is written, intended to disturb and challenge the patriarchal equilibrium that continues to promote forms of knowledge that efface 'others'.

\section{THE ARTICLES AND INTERVIEWS IN THIS SPECIAL ISSUE}

So in bringing this latest special issue of Feminist Encounters to you, we want to engage with popular visual art more deliberately and strategically. We are concerned to engage directly with popular subcultural and independent media because we recognise the special role that such frequently devalued cultural forms take in oppositional political movements. Our special issue on comics brings together contemporary comic and cartoon artists who bring feminist politics into their creative method, whether as themes, through characterisation, or narrative structure or all of those. This collection of essays contributes to a 'history of the present' in popular feminist art practice and seeks to proselytise such creative work. We are very pleased to have included more visual material in this issue of Feminist Encounters too, and we very much hope you enjoy reading it. And now to the articles themselves:

The original contributions to this special issue commence with an interview by Róisín Ryan-Flood with M. J. Barker about their work on The Secrets of Enduring Love, Queer: A graphic history, Gender: A graphic guide (with Jules Scheele), How to Understand Your Gender, and Life isn't Binary (with Alex Iantaffi), Enjoy Sex (How, When, and IF You Want to) (with Justin Hancock), and Rewriting the Rules and The Psychology of Sex. Barker discusses how they came to be part of these projects as well as the usefulness of the comics form to raising and exploring topics as complex as sex and gender. They discuss how this format can contribute to overcoming heteronormativity and other forms of oppression and marginalisation.

The South and Central American articles in this special issue concern feminist comic artists' responses to social justice issues affecting women. Laura Nallely Hernández Nieto and Iván Facundo Rubinstein (Mexico) discuss Cintia Bolio's exhibition on the legacy of the Mirabal sisters who were murdered by Trujillo's regime in the Dominican Republic and use the exhibition to make clear links to current violence against women in Mexico. Amadeo Gandolfo and Pablo Turnes (Argentina), in their article, interview several feminist comics artists and trace the history of feminist comics in Latin America as well as exploring the current situation as the comics artists who have in different ways become involved in current social justice issues such as highlighting gender-based violence.

Comics art in Japan, Hong Kong and China has undergone a number of developments in the last few years regarding the representation of the female form. Sara Sylvester's article is on Rokudenashiko's graphic memoir What is Obscenity?: The story of a good for nothing artist and herpussy (2016), the memoir drew her international recognition and an arrest for indecency in Japan. In her article Sylvester considers the artist's controversial work through an intersectional lens. She uses themes of the body and sexuality, subversion of the monstrous feminine, and feminist activism. In contrast, Kin-Wai Chu's article examines the feminist graphic diaries of Stella So (Hong Kong) and Naoko Takagi (Japan) who write about and draw the smaller events of the everyday experience of solitary living. 
Everyday culture is conventionally associated with femininity and the domestic; however, in these works, the focus is removed from sexuality through a subversive, manga-like infantilising of the female form. In her article, Xiyuan Tan assesses how ethnic minority females are represented in Chinese comics by analysing and comparing two such female characters and suggesting ways in which this type of character can be represented in more meaningful ways.

Seval Erkul's article considers the comics of Bayan Yam, the first women-led caricature publication in Turkey, that takes public positions on socio-political issues. Erkul examines the nature of the comics' feminist activism and how they engage with women's everyday experience in Turkey as well as commenting on socio-political events that affect Turkish women.

Safiyya Hosein contrasts the representation of the first female Muslim Marvel comic hero, Dust, with that of the Egyptian webcomic superhero, Qahera. Hosein finds that the overdetermined symbol of the veil takes on a range of significances in these comics and that the complexity of using the veil is more accurately portrayed in Qahera's stories, which speak more authentically to the everyday experiences of veiled Muslim women in Egypt.

In her contribution, Catherine Mao interviews Congolese comics artist, Fifi Mukuna, discussing her creative journey and the challenges facing female comics artists within the Democratic Republic of Congo. Fifi Mukuna engages socio-politically with everyday African experiences in African countries and in migration to the west. Mukuna describes comics as 'a great medium for educating people and raising awareness' due to their accessibility; however, she now lives in France because her work has antagonised authorities in her home country.

In Rose Richards' interview with Neeske Alexander from South Africa, Alexander describes how she came to be making comics and why these have been useful to her in processing difficult things. Although Alexander is new to the comics world, she shares a number of experiences with other comics artists in this collection, including the realisation that her more controversial topics will not gain mainstream recognition despite (or perhaps because of) their value to a feminist audience.

Promina Shrestha tackles the topic of comics by Nepali women artists and considers the extent to which women artists representing aspects of everyday lives can be considered feminist. Shrestha discusses Nepali feminism and how comics fit into this, pointing out that Nepali feminism is not in itself completely representative of the mix of different cultures and socio-economic classes of Nepal. She discusses the work of seven Nepali women artists over nearly 20 years.

Both Surangama Datta and E. Dawson Varughese write specifically about Indian female queer comics art. Datta uses her study of Amruta Patil's Kari (2008) to examine how this experimental text appropriates the act of looking for a queer feminist protagonist and how Patil uses fluidity as a visual metaphor for Kari's experiences. In Varughese's interview with Neelima P. Aryan, Varughese and Aryan discuss the comic medium as a way of adding layers of complexity to feminisms by combining image and text. The interview makes an argument for having a wider range of culturally and socially situated feminisms, including queer feminisms within the context of urban India.

Debanjana Nayek's article is also about women in Indian comics. In her article she traces how Indian comics engage with gender, from Amar Chitra Katha to contemporary graphic novels. Nayek explains how the gaze has evolved in ways that have allowed women comics artists to represent themselves and their own lives. Her article also takes account of the effects on the comics form of using different digital media.

Aanchal Vij interviews Priya Kuriyan through the lens of the interaction between the individual and the collective in the space of Indian comics. Priya Kuriyan plays with nostalgia and time-bending in her comics in order to help create a better future for Indian women. She has told the stories of famous female figures such as Indira Gandhi, and has also engaged with events of national importance, such as the aftermath of the globally infamous Delhi rape case, through the medium of comics as this makes the complex and often inflammatory subject matter more accessible to a wider audience.

The original contributions to this special issue conclude with a comic by Shromona Das, entitled 'A Reflection on \#Metoo, a Story of Sexual Assault and Victimhood in India'. In this comic Das tackles the subject of her own sexual abuse by a relative. In an interview with HuffPost India ${ }^{5}$, Das explains why the images are black and white:

The white paper was my only friend - I was afraid of being betrayed similarly, that is, in terms of silencing my voice, by my family members. So I started channelling it all through my black Parker pen-for the longest time, I've never parted with that pen. That pen was my one true friend.... For the largest part of my life, black and white became my language - all of these paintings were about domestic settings, everyday objects, toys and violence. I don't remember a single one that didn't talk about violence—and death.

\footnotetext{
5 The interview can be found here: https://www.huffingtonpost.in/2018/10/24/metoo-in-india-a-24-year-old-jnu-studentcalled-out-her-abusers-in-a-powerful-set-of-paintings_a_23570060/
} 
Das' act of drawing her story allowed her to overcome the silencing she experienced and became a subversive act of defiance that allowed her to take her story back.

In addition to the articles and interviews, four books are reviewed. Adam K. Dedman (University of Melbourne, Australia) reviews Rewriting the Victim: Dramatization as research in Thailand's anti-trafficking. Cordelia Freeman (University of Exeter, UK) reviews Perwian Lives Across Borders: Power, exclusion, and home, Janine E. Carlse (University of Cape Town and Stellenbosch University, South Africa) reviews Black Feminism Reimagined: After intersectionality and Po-Han Lee (University of Sussex, UK) reviews the Routledge Handbook of East Asian Gender Studies.

In Feminist Encounters, we are always committed to bringing new feminist criticism and creative work to you available online for free. Feminist Encounters is an open access publication, and our growing readership across the world reflects our commitment to high quality and accessible research. We sincerely hope you enjoy our snapshot of international feminist comic art.

\section{REFERENCES}

Munt, S. R. (2008). Introduction: On lesbians and other animals. In McCauliffe, M. and Tiernan, S. (eds.). Lesbian Lives Volume II Sapphists and Sexologists: Histories of sexualities (pp. xvii-xxxi). Cambridge, UK: Cambridge Scholars Press. Conference Proceedings.

Streeten, N. and Tate, C. eds. (2018) The Inking Woman: 250 years of women cartoon and comic artists in Britain. Oxford, UK: Myriad Editions.

Citation: Munt, S. R. and Richards, R. (2020). Feminist Comics in an International Frame. Feminist Encounters: $A$ Journal of Critical Studies in Culture and Politics, 4(1), 01. https://doi.org/10.20897/femenc/7905

Copyright (C) 2020 by Author/s and Licensed by Lectito BV, Netherlands. This is an open access article distributed under the Creative Commons Attribution License which permits unrestricted use, distribution, and reproduction in any medium, provided the original work is properly cited. 